Journal of Advanced Research in Fluid Mechanics and Thermal Sciences

\title{
Magnetohydrodynamic Effects in Mixed Convection of Ferrofluid Flow at Lower Stagnation Point on Horizontal Circular Cylinder
}

\author{
Siti Hanani Mat Yasin ${ }^{1}$, Muhammad Khairul Anuar Mohamed ${ }^{1}$, Zulkhibri Ismail $^{1}$, Mohd Zuki \\ Salleh ${ }^{1, *}$ \\ Center for Mathematical Sciences, Universiti Malaysia Pahang, 26300 Gambang, Kuantan, Pahang, Malaysia
}

\begin{tabular}{ll} 
ARTICLE INFO & ABSTRACT \\
\hline $\begin{array}{l}\text { Article history: } \\
\text { Received } 26 \text { April } 2021\end{array}$ & $\begin{array}{l}\text { In this paper, mixed convection of ferrofluid containing magnetite, Fe } \mathrm{O}_{4} \text { with } \\
\text { Received in revised form } 10 \text { July } 2021\end{array}$ \\
$\begin{array}{l}\text { Accepted } 15 \text { July } 2021 \\
\text { fvailable online } 12 \text { August } 2021\end{array}$ & $\begin{array}{l}\text { circular cylinder is investigated. The partial differential equation which derived from } \\
\text { the transformation of the dimensional governing equation and non-similarity } \\
\text { transformation with the consideration of the effect of magnetohydrodynamic (MHD) } \\
\text { are solved numerically by using Keller-box method. The influences of an external } \\
\text { magnetic field on ferrofluid flow and heat transfer are then discussed. The results } \\
\text { showed that the viscosity depends on the ferroparticle volume fraction and ferrofluid } \\
\text { temperature. The uniform magnetic field that produced Lorentz force acts as a } \\
\text { Ferrofluid; magnetohydrodynamic; } \\
\text { horizontal circular cylinder; stagnation } \\
\text { point }\end{array} \quad \begin{array}{l}\text { determiner of the trend of fluid movement and has the tendency to control the } \\
\text { cooling rate of the surface. }\end{array}$
\end{tabular}

\section{Introduction}

Numerous theoretical and experimental studies on the nanofluid since Choi and Eastman [1] discovered the potential and capabilities of nanofluid to enhance the thermal conductivity and heat transfer. The thermophysical properties of nanofluid are the crucial aspect to know especially in their thermal conductivity and viscosity. The point of concern in this study is the discovery of magnetic nanofluid behaviour. The magnetic nanofluid or known as ferrofluid which was invented in 1963 by NASA as a rocket fuel classified into two groups which are surfacted ferrofluid (SFF) and ionic ferrofluid (IFF). The difference between these two groups is the nanoparticles molecule coated that prevent agglomeration between nanoparticles which SFF coated with surfactant agent and IFF coated with an electric shell [2]. Ferrofluid contains magnetic nanoparticles such as magnetite $\left(\mathrm{Fe}_{3} \mathrm{O}_{4}\right)$, maghemite $\left(\gamma-\mathrm{Fe}_{2} \mathrm{O}_{3}\right)$, cobalt ferrite $\left(\mathrm{CoFe}_{2} \mathrm{O}_{4}\right)$ and other compounds having iron oxide which suspended in a liquid carrier (water, oil, ethylene, etc.) and exhibit superparamagnetism magnetic behaviour [3]. Therefore, ferrofluid becomes permanently magnetized in the presence of a magnetic field which contributes to low viscosity, easy flowability

\footnotetext{
* Corresponding author.

E-mail address: zuki@ump.edu.my

https://doi.org/10.37934/arfmts.86.1.5263
} 
and low energy. Ferrofluid is synthesized by several methods such as ball milling, co-precipitation and decomposition of the iron carbonyl because it is not found in nature. The research in creating and improving ferrofluid formulations in wide applications such as in electronic devices, military, aerospace and medical [4]. Nowadays, electronic devices like loudspeaker use ferrofluid to avoid the voice coil from overheating $[5,6]$.

The experimental studies have proven the water-based magnetite $\left(\mathrm{Fe}_{3} \mathrm{O}_{4}\right)$ nanofluid can enhance thermal conductivity [7-9]. Hence, the magnetite $\left(\mathrm{Fe}_{3} \mathrm{O}_{4}\right)$ nanoparticles and water which acts as a carrier fluid is considered in this study to understand the ferrofluid flow behaviour in the presence of the magnetic field. The interaction of the magnetic field and fluid emerged the magnetohydrodynamic effect that influences the ferrofluid flow and their thermophysical properties. The fluid behaviour will change according to the fluid flow at different geometries and assumptions [10]. Sheikholeslami et al., [11], Sheikholeslami and Ganji [12], Sheikholeslami and Shehzad [13], Sheikholeslami and Ganji [14] and many other researchers [15-17] have done extensive researches about the magnetohydrodynamic effect and viscosity of ferrofluid on various surfaces. Most of the results revealed the magnetite $\left(\mathrm{Fe}_{3} \mathrm{O}_{4}\right)$ nanoparticles volume fraction (ferroparticles volume fraction), thermal radiation and magnetic parameters are the factors that enhance the heat transfer and velocity of ferrofluid with water-based.

The above studies motivated the authors to concentrate on the exploration of the ferrofluid flow on a horizontal circular cylinder. The effect of magnetohydrodynamic with the presence of thermal radiation in ferrofluid flow on a horizontal circular cylinder is investigated by implementing the Tiwari and Das [18] model.

\section{Methodology}

A horizontal circular cylinder of radius $a$ embedded in a ferrofluid which is heated cylinder occur when $T_{w}>T_{\infty}$ for assisting flow and cooled cylinder occurs when $T_{w}<T_{\infty}$ for opposing flow where $T_{w}$ is constant surface temperature and $T_{\infty}$ is ambient temperature with free stream velocity, $U_{\infty}$ far flow from the cylinder as shown in Figure 1.

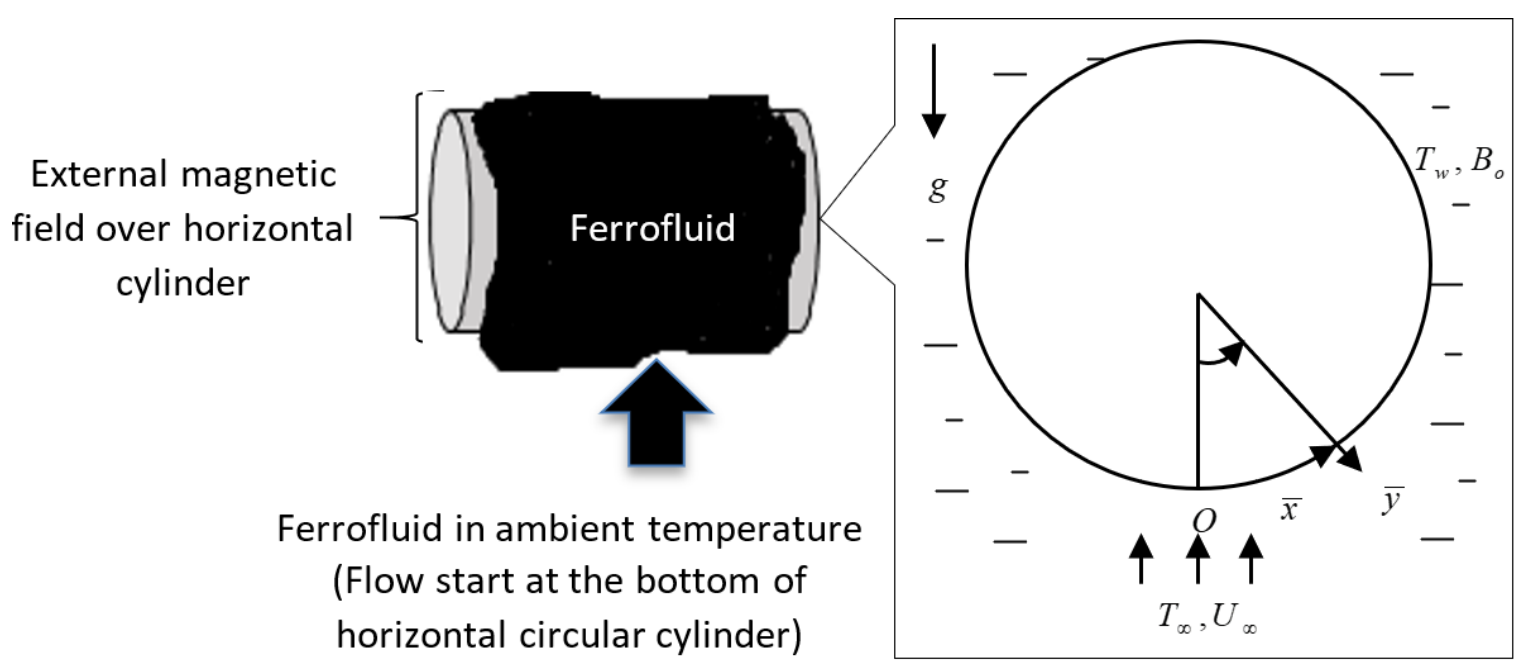

Fig. 1. Physical model and coordinate system 
The ferrofluid flow starts with a lower stagnation point, $\bar{x}=0$ where the orthogonal coordinates of $\bar{x}$ and $\bar{y}$ are measured along the horizontal cylinder surface under the assumptions that the steady, two-dimensional and laminar mixed convection boundary layer flows of incompressible ferrofluid. Here, a uniform transverse magnetic field of strength, $B_{o}$ is assumed to be applied perpendicularly to the horizontal cylinder surface where the magnetic Reynolds number is assumed to be small, and thus the induced magnetic field is negligible. The surface of cylinder is subjected to a constant wall temperature and exposed to the thermal radiation is considered. Further, the ferrofluid with ferroparticles (magnetite, $\mathrm{Fe}_{3} \mathrm{O}_{4}$ ) dispersant is suspended in a base fluid (water) are assumed as Newtonian fluid and behave as single-phase fluid to be in thermal equilibrium and no-slip velocity condition. Employing the Boussinesq approximation and the assumption of boundary layer approximation is valid with the source term mentioned above, the dimensional governing equations of fluid flow and heat transfer for ferrofluid are obtained as $[19,20]$

$$
\begin{aligned}
& \frac{\partial \bar{u}}{\partial \bar{x}}+\frac{\partial \bar{v}}{\partial \bar{y}}=0 \\
& \bar{u} \frac{\partial \bar{u}}{\partial \bar{x}}+\bar{v} \frac{\partial \bar{u}}{\partial \bar{y}}=\bar{u}_{e} \frac{\partial \bar{u}_{e}}{\partial \bar{x}}+v_{f f} \frac{\partial^{2} \bar{u}}{\partial \bar{y}^{2}}+\frac{(\rho \beta)_{f f}}{\rho_{f f}} g\left(T-T_{\infty}\right) \sin \frac{\bar{x}}{a}-\frac{\sigma_{f f} B_{o}^{2}}{\rho_{f f}}\left(\bar{u}-\bar{u}_{e}\right), \\
& \bar{u} \frac{\partial T}{\partial \bar{x}}+\bar{v} \frac{\partial T}{\partial \bar{y}}=\alpha_{f f} \frac{\partial^{2} T}{\partial \bar{y}^{2}}-\frac{1}{\left(\rho C_{p}\right)_{f f}} \frac{\partial q_{r}}{\partial \bar{y}}
\end{aligned}
$$

subject to the boundary conditions

$$
\begin{aligned}
& \bar{u}(\bar{x}, 0)=\bar{v}(\bar{x}, 0)=0, T(\bar{x}, 0)=T_{w} \text { at } \bar{y}=0, \\
& \bar{u}(\bar{x}, \infty) \rightarrow \bar{u}_{e}(x), T(\bar{x}, \infty) \rightarrow T_{\infty} \text { as } \bar{y} \rightarrow \infty
\end{aligned}
$$

where $\bar{u}$ and $\bar{v}$ indicate the velocity components along the $\bar{x}$ and $\bar{y}$ axes, respectively while $\bar{u}_{e}(x)=U_{\infty} \sin (\bar{x} / a)$ refer to external velocity. Meanwhile, the effective thermophysical properties definition of ferrofluid (subscript $f f$ ) can be expressed in terms of base fluid (subscript $f$ ), ferroparticles (subscript $s$ ) and ferroparticles volume fraction $\phi$ as follows $[9,11,21]$

- dynamic viscosity: $\mu_{f f}=\frac{\mu_{f}}{(1-\phi)^{2.5}}$,

- kinematic viscosity: $v_{f f}=\frac{\mu_{f f}}{\rho_{f f}}$,

- thermal diffusivity: $\alpha_{f f}=\frac{k_{f f}}{\rho_{f f}\left(C_{p}\right)_{f f}}$

- effective density: $\rho_{f f}=(1-\phi) \rho_{f}+\phi \rho_{s}$,

- buoyancy coefficient: $(\rho \beta)_{f f}=(1-\phi)(\rho \beta)_{f}+\phi(\rho \beta)_{s}$, 
- effective heat capacity: $\left(\rho C_{p}\right)_{f f}=(1-\phi)\left(\rho C_{p}\right)_{f}+\phi\left(\rho C_{p}\right)_{s}$,

- electrical conductivity: $\frac{\sigma_{f f}}{\sigma_{f}}=1+\frac{3\left(\frac{\sigma_{s}}{\sigma_{f}}-1\right) \phi}{\left(\frac{\sigma_{s}}{\sigma_{f}}+2\right)-\left(\frac{\sigma_{s}}{\sigma_{f}}-1\right) \phi}$,

- thermal conductivity: $\frac{k_{f f}}{k_{f}}=\frac{k_{s}+2 k_{f}-2 \phi\left(k_{f}-k_{s}\right)}{k_{s}+2 k_{f}+\phi\left(k_{f}-k_{s}\right)}$,

where $g$ is the gravity acceleration, $\beta$ is the thermal expansion, $T$ is ferrofluid temperature and $\alpha$ is the thermal diffusivity. It is worth mentioning that the proposed models of the dynamic viscosity and thermal conductivity are applicable to uniformly sized and spherical particles which statistically homogenous with randomly dispersed as given by Brinkman [22] and Maxwell [23], respectively. Next, the thermophysical properties of base fluid (water) and ferroparticles (magnetite, $\mathrm{Fe}_{3} \mathrm{O}_{4}$ ) have been listed in Table 1.

\section{Table 1}

Thermophysical properties of base fluid and ferroparticles [12,21]

\begin{tabular}{lll}
\hline Physical Properties & Water & Magnetite $\left(\mathrm{Fe}_{3} \mathrm{O}_{4}\right)$ \\
\hline$\rho\left(\mathrm{kg} \cdot \mathrm{m}^{-3}\right)$ & 997.1 & 5200 \\
$C_{p}\left(\mathrm{~J} \cdot \mathrm{kg}^{-1} \cdot \mathrm{K}^{-1}\right)$ & 4179 & 670 \\
$k\left(\mathrm{~W} \cdot \mathrm{m}^{-1} \cdot \mathrm{K}^{-1}\right)$ & 0.613 & 6 \\
$\sigma(\Omega \cdot \mathrm{m})^{-1}$ & 0.05 & 25000 \\
$\beta(\mathrm{K})^{-1}$ & $21 \times 10^{-5}$ & $1.18 \times 10^{-5}$ \\
\hline
\end{tabular}

In consideration of thermal radiation in this study, the Rosseland approximation is used where the radiative heat flux $q_{r}$ is defined as

$$
q_{r}=-\frac{4 \sigma^{*}}{3 k^{*}} \frac{\partial T^{4}}{\partial \bar{y}}
$$

where $\sigma^{*}$ and $k^{*}$ are the Stefan-Boltzmann constant and the mean absorption coefficient, respectively. Now, the term $T^{4}$ is expressed as a linear function of the temperature difference within the flow is assumed to be sufficiently small expanding in a Taylor series about $T_{\infty}$ and neglecting the higher-order terms (considering up to second term) in the Eq. (3), which becomes

$$
\bar{u} \frac{\partial T}{\partial \bar{x}}+\bar{v} \frac{\partial T}{\partial \bar{y}}=\alpha_{f f} \frac{\partial^{2} T}{\partial \bar{y}^{2}}+\frac{1}{\left(\rho C_{p}\right)_{f f}} \frac{16 \sigma^{*} T_{\infty}^{3}}{3 k^{*}} \frac{\partial^{2} T}{\partial \bar{y}^{2}}
$$


Next, the variables are introduced to transform the governing partial differential equations into dimensionless as follows

$$
x=\frac{\bar{x}}{a}, \quad y=\operatorname{Re}^{1 / 2} \frac{\bar{y}}{a}, \quad u=\frac{\bar{u}}{U_{\infty}}, \quad v=\operatorname{Re}^{1 / 2} \frac{\bar{v}}{U_{\infty}}, \quad u_{e}(x)=\frac{\bar{u}_{e}(x)}{U_{\infty}}, \quad \theta(\eta)=\frac{T-T_{\infty}}{T_{w}-T_{\infty}},
$$

where $\theta$ is the rescaled dimensionless temperature of the ferrofluid and $\operatorname{Re}=\frac{U_{\infty} a}{v_{f}}$ is the local Reynolds number. The implemented variables (7) and the effective thermophysical properties definition in Eq. (1), Eq. (2) and Eq. (6) becomes

$\frac{\partial u}{\partial x}+\frac{\partial v}{\partial y}=0$

$u \frac{\partial u}{\partial x}+v \frac{\partial u}{\partial y}=u_{e} \frac{\partial u_{e}}{\partial x}+\frac{v_{f f}}{v_{f}} \frac{\partial^{2} u}{\partial y^{2}}+\frac{(1-\phi) \rho_{f}+\phi(\rho \beta)_{s} / \beta_{f}}{(1-\phi) \rho_{f}+\phi \rho_{s}} \lambda \theta \sin x-\frac{\sigma_{f f}}{\sigma_{f}} \frac{\rho_{f}}{\rho_{f f}} M\left(u-u_{e}\right)$,

$u \frac{\partial \theta}{\partial x}+v \frac{\partial \theta}{\partial y}=\frac{1}{\operatorname{Pr}} \frac{\left(\rho C_{p}\right)_{f}}{\left(\rho C_{p}\right)_{f f}}\left(\frac{k_{f f}}{k_{f}}+\frac{4}{3} N r\right) \frac{\partial^{2} \theta}{\partial y^{2}}$,

subject to the boundary conditions

$$
\begin{aligned}
& u(x, 0)=0, v(x, 0)=0, \theta(x, 0)=1, \\
& u(x, \infty) \rightarrow u_{e}, \quad \theta(x, \infty) \rightarrow 0,
\end{aligned}
$$

where the magnetic parameter, the mixed convection parameter, the Grashof number, the Prandtl number and radiation parameter are expressed as

$$
M=\frac{\sigma_{f} a^{2} B_{o}^{2}(x)}{\mu_{f} \operatorname{Re}}, \quad \lambda=\frac{G r}{\operatorname{Re}^{2}}, \quad G r=\frac{g \beta_{f}\left(T_{w}-T_{\infty}\right) a^{3}}{v_{f}^{2}}, \quad \operatorname{Pr}=\frac{v_{f}\left(\rho C_{p}\right)_{f}}{k_{f}}, \quad N r=\frac{4 \sigma^{*} T_{\infty}^{3}}{k^{*} k_{f}}
$$

It is noteworthy that the two cases exist as mentioned above which is $\lambda>0$ indicates assisting flow (heated cylinder) and $\lambda<0$ indicates opposing flow (cooled cylinder) where $\lambda \rightarrow 0 \quad\left(G r_{x}=0\right)$ is dominated by forced convection while $\lambda \rightarrow \infty \quad\left(\operatorname{Re}_{x} \approx 0\right)$ represents the free convection. The following non-similarity functions are introduced to reduce the number of dependent variables given by

$$
\psi=x f(x, y), \quad \theta=\theta(x, y)
$$

where $\psi$ is the stream function defined as $u=\frac{\partial \psi}{\partial y}$ and $v=-\frac{\partial \psi}{\partial x}$ which identically satisfies Eq. (8). 
Hence, by substituted Eq. (13) into Eq. (9) and Eq. (10), the following partial differential equations are obtained

$$
\begin{aligned}
& \frac{1}{(1-\phi)^{2.5}\left[1-\phi+\left(\phi \rho_{s}\right) /\left(\rho_{f}\right)\right]} \frac{\partial^{3} f}{\partial y^{3}}+f \frac{\partial^{2} f}{\partial y^{2}}-\left(\frac{\partial f}{\partial y}\right)^{2}+\frac{(1-\phi) \rho_{f}+\phi(\rho \beta)_{s} / \beta_{f}}{(1-\phi) \rho_{f}+\phi \rho_{s}} \lambda \theta \frac{\sin x}{x} \\
& +\frac{\sin x \cos x}{x}-\frac{\sigma_{f f} / \sigma_{f}}{(1-\phi)+\phi\left(\rho_{s} / \rho_{f}\right)} M\left(\frac{\partial f}{\partial y}-\frac{\sin x}{x}\right)=x\left(\frac{\partial f}{\partial y} \frac{\partial^{2} f}{\partial x \partial y}-\frac{\partial f}{\partial x} \frac{\partial^{2} f}{\partial y^{2}}\right), \\
& \frac{1}{\operatorname{Pr}} \frac{\left(\rho C_{p}\right)_{f}}{\left(\rho C_{p}\right)_{f f}}\left(\frac{k_{f f}}{k_{f}}+\frac{4}{3} N r\right) \frac{\partial^{2} \theta}{\partial y^{2}}+f \frac{\partial \theta}{\partial y}=x\left(\frac{\partial f}{\partial y} \frac{\partial \theta}{\partial x}-\frac{\partial f}{\partial x} \frac{\partial \theta}{\partial y}\right) .
\end{aligned}
$$

The boundary conditions (11) becomes

$$
\begin{aligned}
& f(x, 0)=0, \quad \frac{\partial f}{\partial y}(x, 0)=0, \quad \theta(x, 0)=1, \\
& \frac{\partial f}{\partial y}(x, \infty) \rightarrow \frac{\sin x}{x}, \quad \theta(x, \infty) \rightarrow 0
\end{aligned}
$$

The position of ferrofluid flow at the lower stagnation point $(x \approx 0)$ of a horizontal circular cylinder occur when Thus, the Eq. (14) and Eq. (15) will be reduced to the following ordinary differential equations that the $f^{\prime}$ and $\theta^{\prime}$ denotes the differentiation with respect to the variable

$$
\begin{aligned}
& \frac{1}{(1-\phi)^{2.5}\left[1-\phi+\left(\phi \rho_{s}\right) /\left(\rho_{f}\right)\right]} f^{\prime \prime \prime}+f f^{\prime \prime}-f^{\prime 2}+\frac{(1-\phi) \rho_{f}+\phi(\rho \beta)_{s} / \beta_{f}}{(1-\phi) \rho_{f}+\phi \rho_{s}} \lambda \theta+1 \\
& -\frac{\sigma_{f f} / \sigma_{f}}{(1-\phi)+\phi\left(\rho_{s} / \rho_{f}\right)} M\left(f^{\prime}-1\right)=0, \\
& \frac{1}{\operatorname{Pr}} \frac{\left(\rho C_{p}\right)_{f}}{\left(\rho C_{p}\right)_{f f}}\left(\frac{k_{f f}}{k_{f}}+\frac{4}{3} N r\right) \theta^{\prime \prime}+f \theta^{\prime}=0,
\end{aligned}
$$

and the boundary conditions

$$
\begin{aligned}
& f(0)=0, \quad f^{\prime}(0)=0, \quad \theta(0)=1, \\
& f^{\prime}(\infty) \rightarrow 1, \quad \theta(\infty) \rightarrow 0 .
\end{aligned}
$$

It should be noted that the velocity profiles and temperature distributions at the lower stagnation point of a horizontal circular cylinder can be obtained from the following relations:

$u=f^{\prime}(y)$ and $\theta=\theta(y)$. 


\section{Results}

The Keller-box method is implemented to find the numerical solution of the Eq. (14) and Eq. (15) with the boundary conditions (16) as described in a study by Yasin et al., [24] for velocity, temperature and reduced Nusselt number components at the lower stagnation point, $x \approx 0$ of a horizontal circular cylinder. Then, the step size $\Delta x=\Delta y=0.005$ and the boundary layer thickness $y_{\infty}=6$ have been set throughout this investigation in the Matlab numerical codes. The accuracy of the numerical method and Matlab programme codes used are verified by comparing with previously reported results. The results from El-Zahar et al., [19] and Merkin [20] are chosen to make a comparison where they used the hybrid linearization-Chebyshev spectral method (HLCSM) and Newton-Raphson method, respectively. In particular, the best comparative results is selected from the other study that has the same momentum and energy equation as well as the same boundary conditions when that equations simplify to the suitable conditions but using the different method of solving.

Table 2 shows the present results are found in good agreement with previously published results for various values of $\lambda$ (assisting flow and opposing flow) when Newtonian fluid $(\phi=0)$ and $\operatorname{Pr}=1$ in the absence of magnetic field strength and thermal radiation ( $M=N r=0)$ at the lower stagnation of horizontal circular cylinder. Hence, the present numerical method and Matlab programme codes work accurately with effectively and efficiently. The effect of magnetic field strength $M$, ferroparticles volume fraction, $\phi$ and thermal radiation, $N r$ for assisting and opposing flow towards velocity, temperature and reduced Nusselt number at lower stagnation of a horizontal circular cylinder with $\operatorname{Pr}=6.2$ (water) are discussed below. The phenomenology trend of these effects or called pertinent parameter is measured within the range of $-1 \leq \lambda \leq 3,0 \leq \phi \leq 0.1$, $0 \leq M \leq 0.1$ and $0 \leq N r \leq 2$ where the value of the parameters equals zero means the parameter is absent from the equations such as $\phi$ represents pure fluid water without the $\mathrm{Fe}_{3} \mathrm{O}_{4}$ particles.

\section{Table 2}

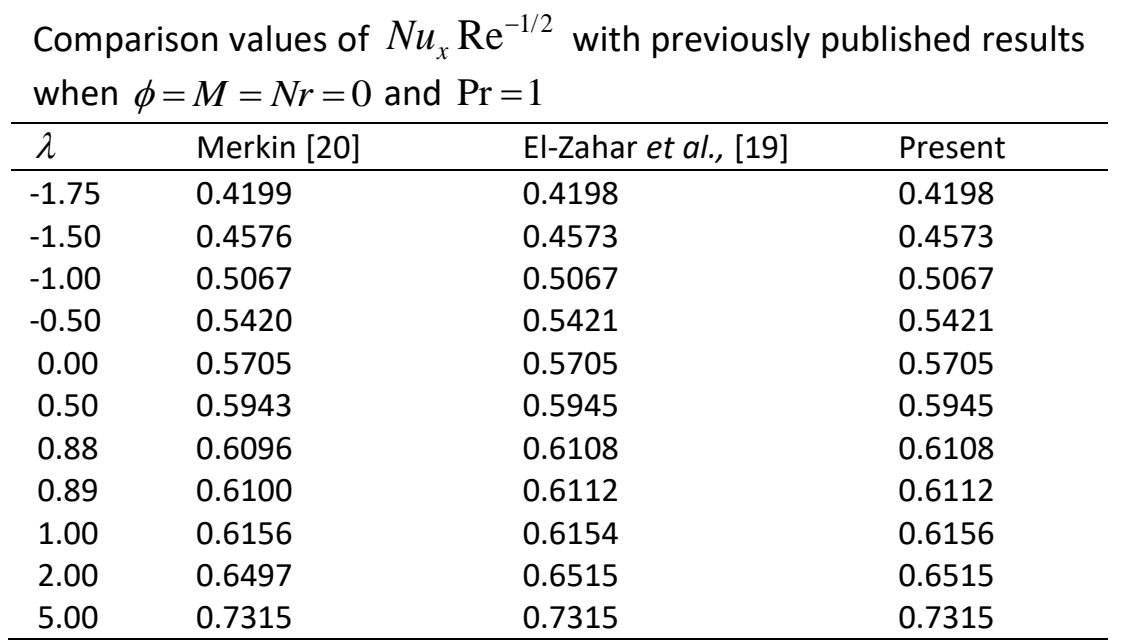

It is important to emphasise that the result found (see Figure 2 and Figure 4) for velocity profile is not horizontal asymptote at $f^{\prime}(\infty)=1$ when the presence of the magnetic field at lower stagnation on a horizontal circular cylinder. However, the temperature profile (see Figure 3 and Figure 5) is horizontal asymptote at $\theta(\infty) \rightarrow 0$ with or without exposure to the magnetic field. Figure 4 until 11 depict the magnetohydrodynamic flow of ferrofluid for assisting and opposing flow 
in the existence of Lorentz force and buoyancy force with the fixed parameter of $\lambda=-1, \lambda=1$, $\phi=0.01, M=0.1$ and $N r=1$ as shown.

Figure 4 and Figure 5 illustrate the increment of the mixed convection parameter elevates the velocity of ferrofluid and significantly reduced the temperature for assisting flow. Conversely, the different phenomenon occurs to the opposing flow. Physically, the heat transfer from a heated cylinder to ferrofluid will reduce the viscosity of the fluid and speed up the fluid motion but change as Lorentz force enhance. This result shows the buoyancy force has the same upward direction as ferrofluid flow tends to accelerate the fluid flow although confront with the Lorentz force. As pointed out by Singh and Gohil [25], the magnetic field imposed at vertical $y$-direction generates the Lorentz force at horizontal $x$-direction in the opposite direction of the fluid and affects the buoyancy force. Besides, this results accordance with Sheikholeslami and Shehzad [13] where the temperature diminishing due to existence of buoyancy force and Lorentz force.

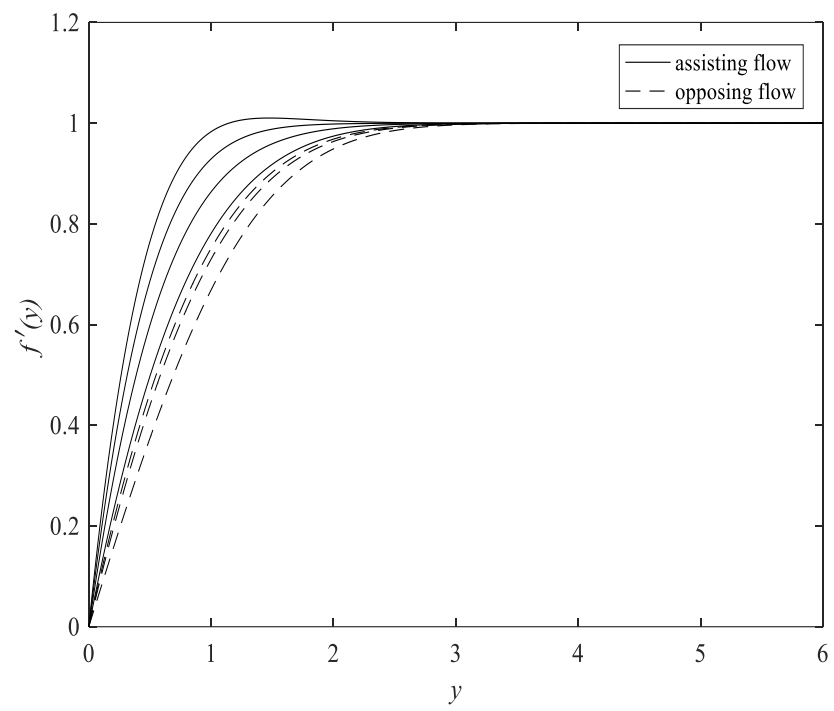

Fig. 2. Velocity profile, $f^{\prime}(y)$ for different value of $\lambda$ when $\phi=0.01, M=0$ and $N r=1$

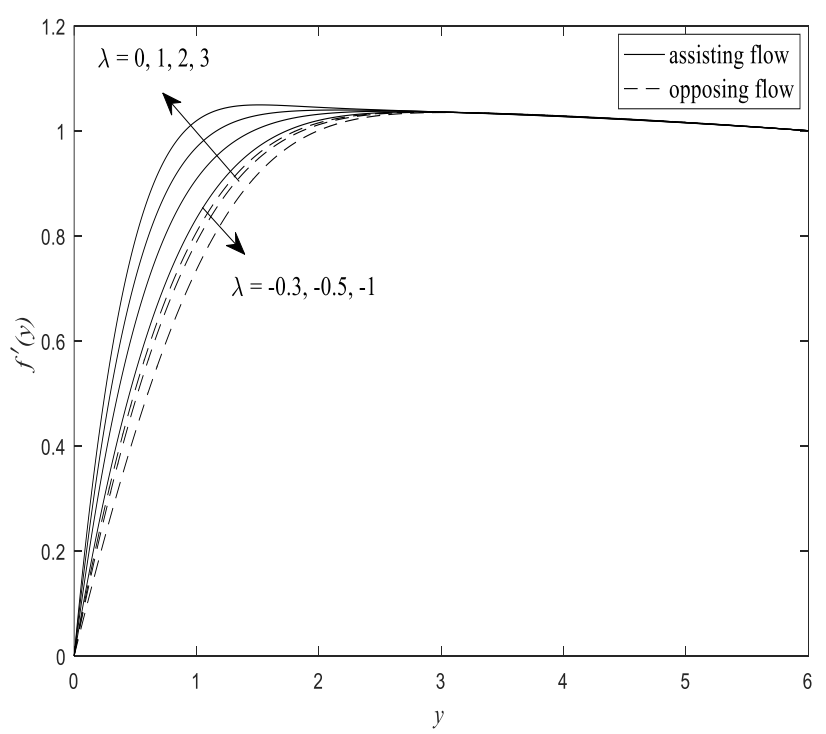

Fig. 4. Velocity profile, $f^{\prime}(y)$ for different value of $\lambda$ when $\phi=0.01, M=0.1$ and $\phi=0.01, M=0$

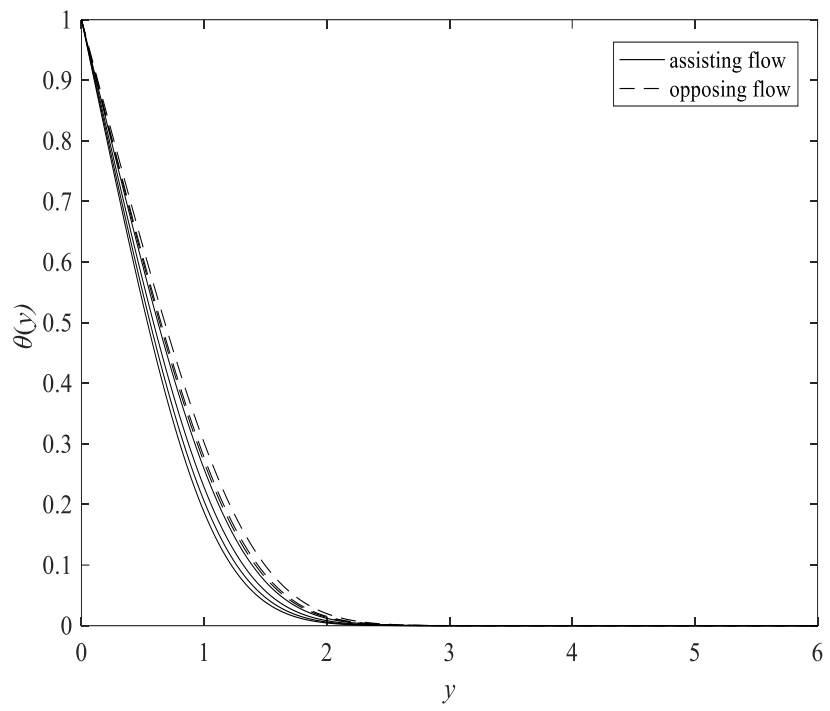

Fig. 3. Temperature profile, $\theta(y)$ for different value of $\lambda$ when $\phi=0.01, M=0$ and $N r=1$

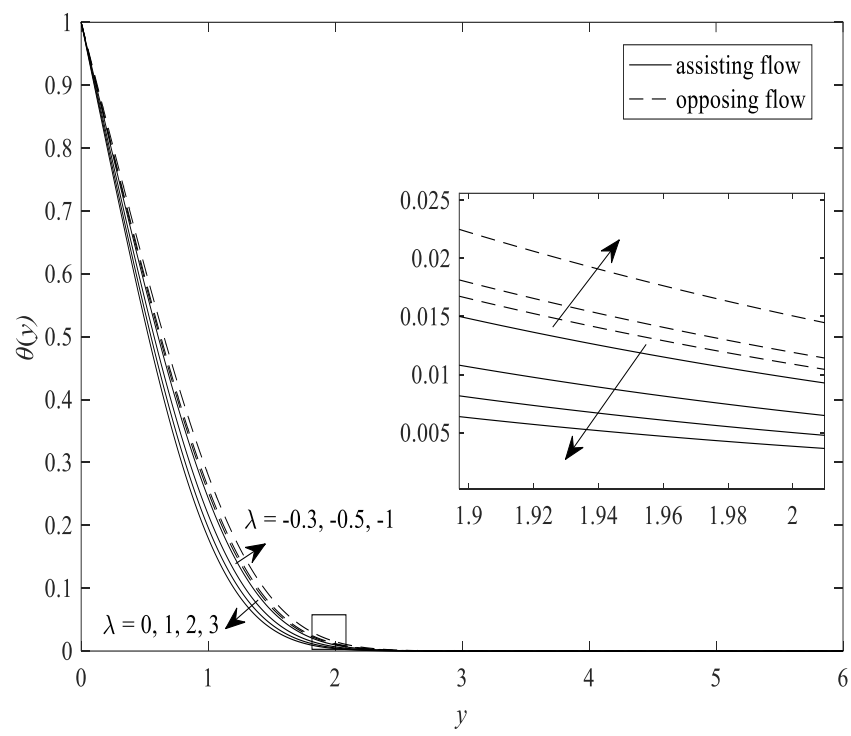

Fig. 5 Temperature profile, $\theta(y)$ for different value of $\lambda$ when $\phi=0.01, M=0.1$ and $\phi=0.01, M=0$ 
Figure 6 illustrates the increases in ferroparticles volume fraction cause the decline of ferrofluid velocity for assisting flow but improve the velocity of ferrofluid for opposing flow which increases and decreases the momentum boundary layer thickness, respectively. It is noticed that through the experiment result by Malekzadeh et al., [8] and Toghraie et al., [26] the viscosity of $\mathrm{Fe}_{3} \mathrm{O}_{4}$ particles with water-based is observed to increase because of the increment in the ferroparticles volume fraction. In assisting flow, the buoyancy force cannot assist the ferrofluid flow when the Lorentz force and the high viscosity of ferrofluid suppress the ferrofluid movement despite the ferrofluid temperature is augment as shown in Figure 7.

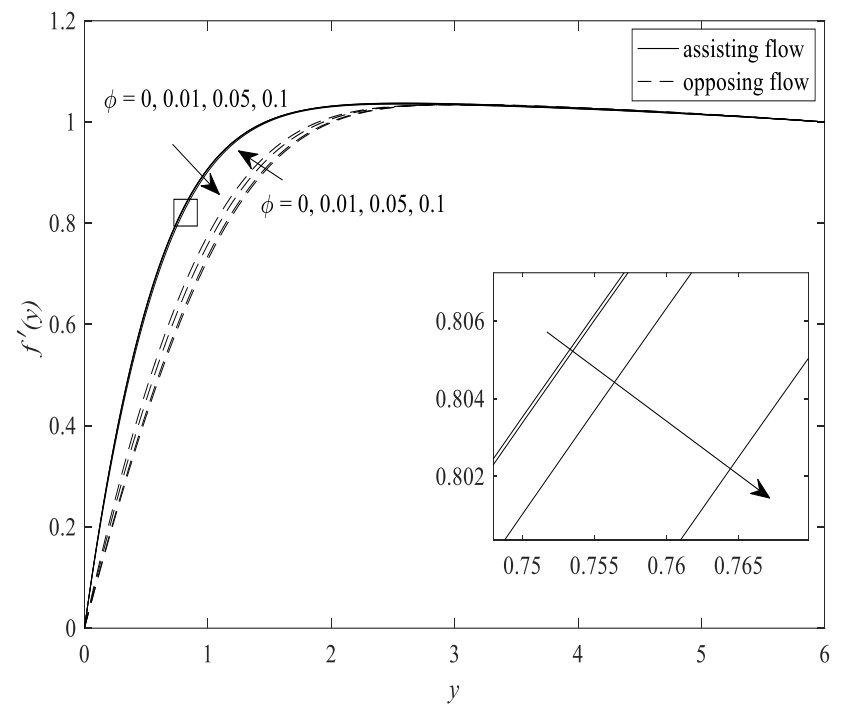

Fig. 6. Velocity profile, $f^{\prime}(y)$ for different value of $\phi$ when $M=0.1$ and $\phi=0.01, M=0$

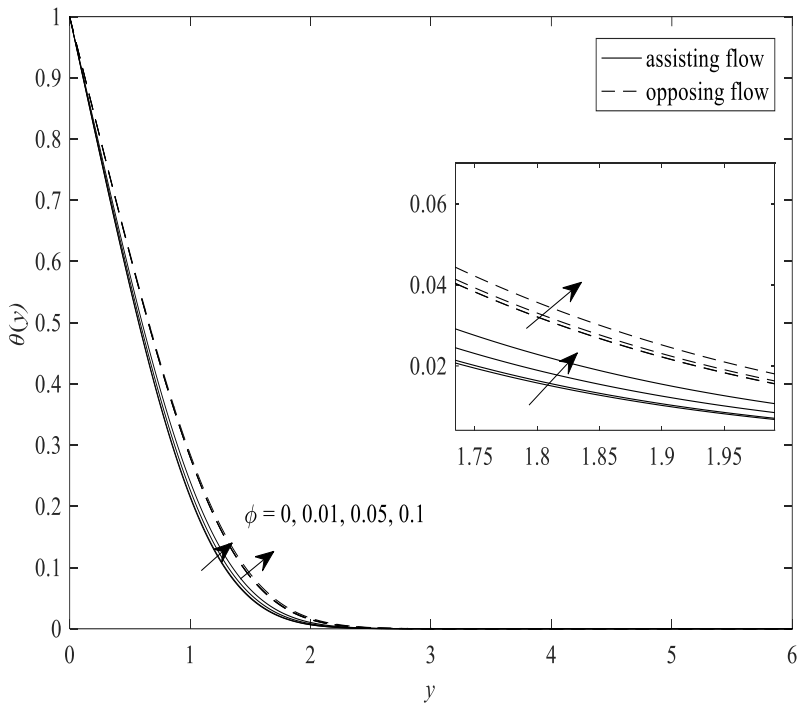

Fig. 7. Temperature profile, $\theta(y)$ for different value of $\phi$ when $M=0.1$ and $\phi=0.01, M=0$

The effect of magnetic parameter on the velocity profile and temperature profile is portrayed in Figure 8 and Figure 9 respectively. Figure 8 demonstrated that the increment in the magnetic parameter elevates the velocity of ferrofluid and diminish the momentum boundary layer thickness for assisting and opposing flow. This result elucidates the phenomenon raises when the magnetic field applied to the surface and presence the Lorentz force in parallel with the reduction of the temperature and the thermal boundary layer as illustrated in Figure 9. Physically, ferrofluid will lose the magnetic properties when it is heated to a high enough temperature. Therefore, the upsurge of the magnetic parameter in Figure 9 leads to a decline in the ferrofluid temperature and increases the magnetism of ferrofluid as well as has the potential to increment the velocity of ferrofluid whilst its magnetic property is enhanced and the strength increase.

Figure 10 and Figure 11 reveal the impact of thermal radiation in assisting flow and opposing flow. It can be seen that the thermal radiation parameter is enlarging, where the velocity of ferrofluid will enhance and momentum boundary layer thickness diminish as depicted in Figure 10 for assisting flow. Nevertheless, the reversed trend exists towards the opposing flow in spite of the temperature of ferrofluid increases as plotted in Figure 11. The increment of thermal radiation causes the temperature of ferrofluid and the thermal boundary layer thickness to increase. These results were similar as reported by Sheikholeslami and Shehzad [13] where the increment of the thermal radiation parameter has a major impact on ferrofluid motion. 


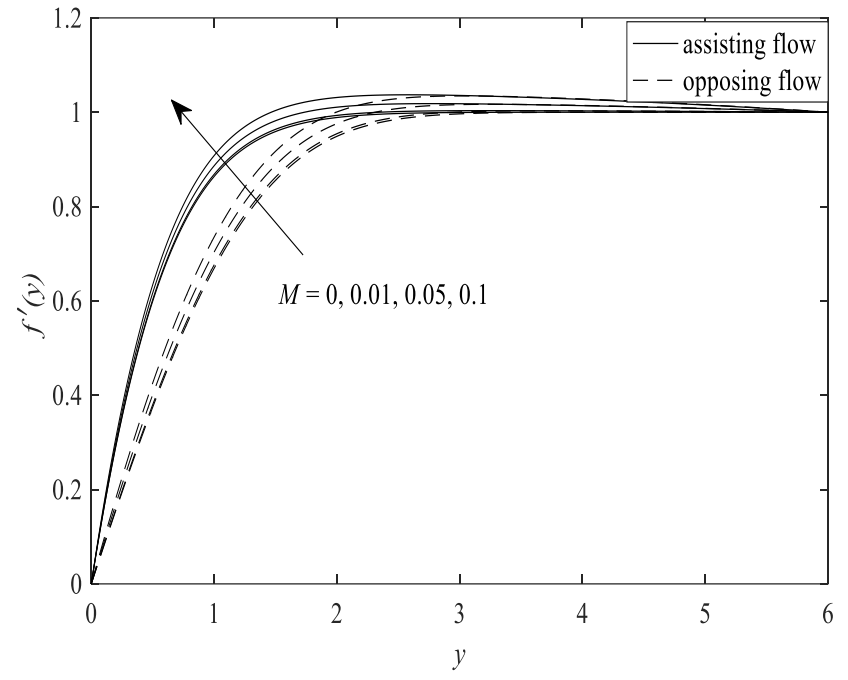

Fig. 8. Velocity profile, $f^{\prime}(y)$ for different value of $M$ when $\phi=0.01$ and $\phi=0.01, M=0$

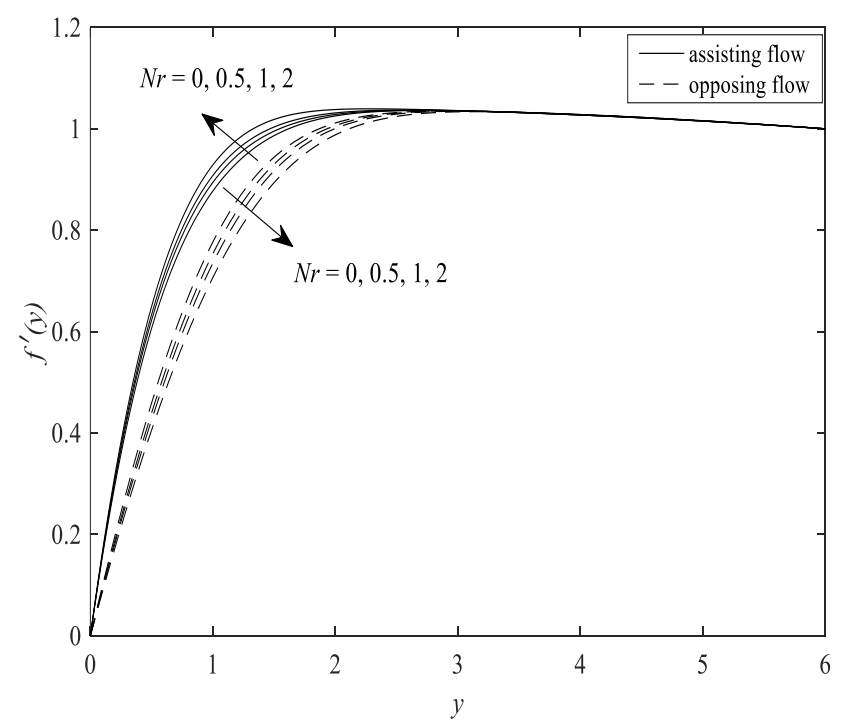

Fig. 10. Velocity profile, $f^{\prime}(y)$ for different value of $N r$ when $\phi=0.01$ and $M=0.1$

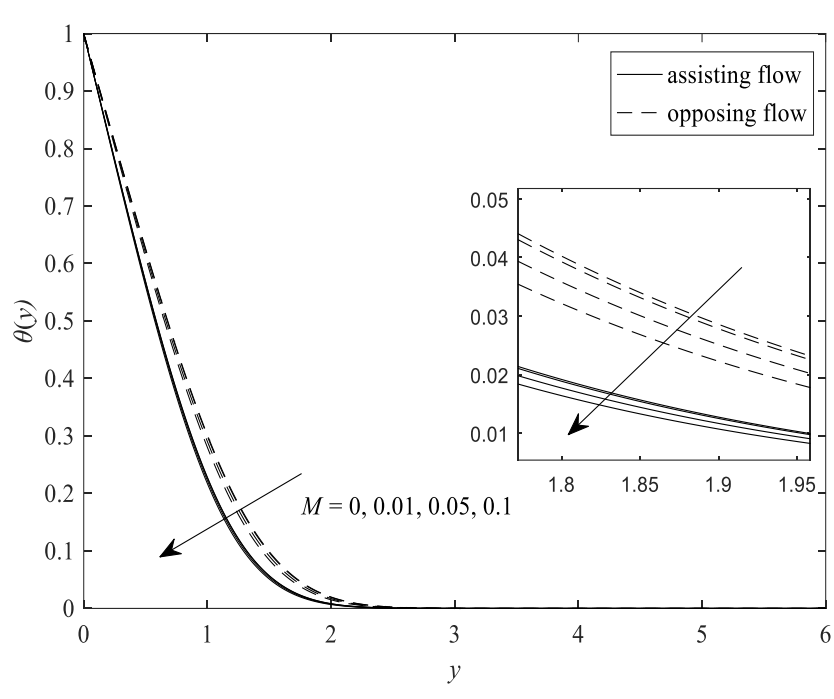

Fig. 9. Temperature profile, $\theta(y)$ for different value of $M$ when $\phi=0.01$ and $\phi=0.01, M=0$

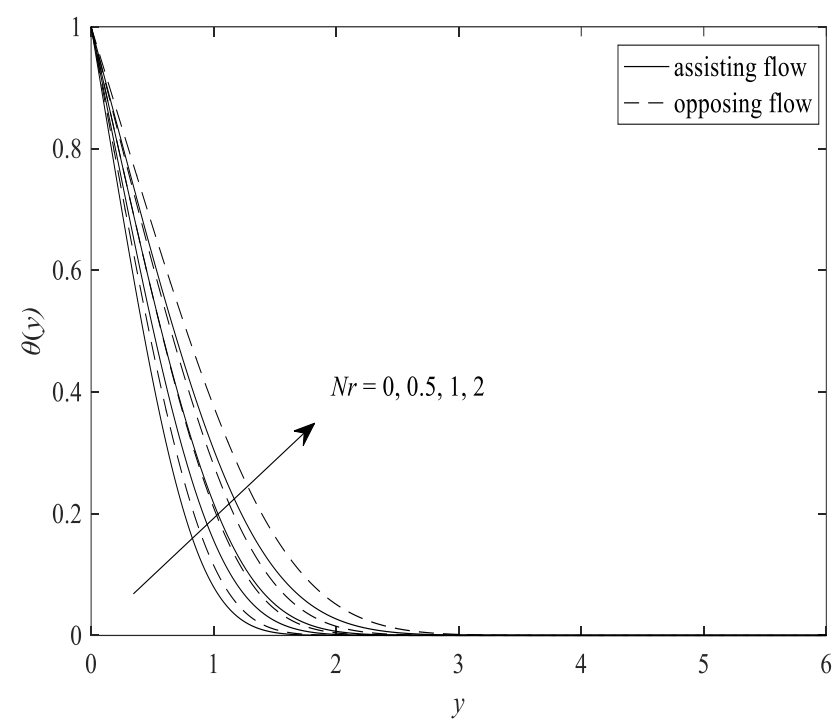

Fig. 11. Temperature profile, $\theta(y)$ for different value of $N r$ when $\phi=0.01$ and $M=0.1$

\section{Conclusions}

The effect of magnetohydrodynamic flow in mixed convection heat transfer of ferrofluid at stagnation point with the presence of thermal radiation on a horizontal circular cylinder has been investigated. The Keller-box method is used to solve the governing equations in which the influence of the Lorentz force and the buoyancy force is scrutinized for assisting and opposing flows. The critical discovery of the study is that the velocity of ferrofluid depends on the viscosity and temperature of the fluid and the phenomena change when the Lorentz force exists. This phenomenon occurs will affect the buoyancy force with the Lorentz force flowing in the opposite direction to the fluid movement and suppress it. It is substantiated not impossible to alter the thermophysical properties and the superparamagnetism magnetic behaviour exhibit in ferrofluid when the applied magnetic field is on the cylinder. The reversed phenomenon takes place when the ferroparticle volume fraction increases where the velocity of ferrofluid getting decrement for 
assisting flow despite the temperature of ferrofluid augment and causes the viscosity to decrease. This observed that the viscosity of ferrofluid is not only a determiner to measure the velocity of ferrofluid but the Lorentz force and buoyancy force has an imperative effect to investigate the fluid flow.

\section{Acknowledgement}

The author would like to thank the Ministry of Higher Education Malaysia for providing financial support under the Fundamental Research Grant Scheme (FRGS/1/2019/STG06/UMP/02/1) (University reference RDU1901124) and Universiti Malaysia Pahang for additional financial support under the Internal Research grant (PGRS1903194).

\section{References}

[1] Choi, S. US, and Jeffrey A. Eastman. Enhancing thermal conductivity of fluids with nanoparticles. No. ANL/MSD/CP-84938; CONF-951135-29. Argonne National Lab., IL (United States), 1995.

[2] Scherer, Claudio, and Antonio Martins Figueiredo Neto. "Ferrofluids: properties and applications." Brazilian Journal of Physics 35, no. 3A (2005): 718-727. https://doi.org/10.1590/S0103-97332005000400018

[3] Rosensweig, Ronald E. Ferrohydrodynamics. New York: Cambridge University Press, 1985.

[4] Yusefi, Mostafa, Shameli K, and Sukri SNAM. Magnetic Nanoparticles In Hyperthermia Therapy: A Mini-Review. J Res Nanosci Nanotechnol 2 (2021): 51-60. https://doi.org/10.37934/irnn.2.1.5160

[5] Tsuda, Shiro, and Ronald E. Rosensweig. "Ferrofluid centered voice coil speaker." U.S. Patent 7,729,504, issued June 1, 2010. https://doi.org/10.1121/1.3554777

[6] Rosensweig, Ronald E., Yuki Hirota, Sayaka Tsuda, and K. Raj. "Study of audio speakers containing ferrofluid." Journal of Physics: Condensed Matter 20, no. 20 (2008): 204147. https://doi.org/10.1088/09538984/20/20/204147

[7] Haiza, H., I. I. Yaacob, and Ahmad Zahirani Ahmad Azhar. "Thermal Conductivity of Water Based Magnetite Ferrofluids at Different Temperature for Heat Transfer Applications." In Solid State Phenomena, vol. 280, pp. 3642. Trans Tech Publications Ltd, 2018. https://doi.org/10.4028/www.scientific.net/SSP.280.36

[8] Malekzadeh, A., A. R. Pouranfard, N. Hatami, A. Kazemnejad Banari, and M. R. Rahimi. "Experimental Investigations on the Viscosity of Magnetic Nanofluids under the Influence of Temperature, Volume Fractions of Nanoparticles and External Magnetic Field." Journal of Applied Fluid Mechanics 9, no. 2 (2016). https://doi.org/10.18869/acadpub.jafm.68.225.24022

[9] Sundar, L. Syam, Manoj K. Singh, and Antonio CM Sousa. "Investigation of thermal conductivity and viscosity of $\mathrm{Fe}_{3} \mathrm{O}_{4}$ nanofluid for heat transfer applications." International Communications in Heat and Mass Transfer 44 (2013): 7-14. https://doi.org/10.1016/j.icheatmasstransfer.2013.02.014

[10] Darus, Amer Nordin. Analisis pemindahan haba: Olakan. Dewan Bahasa dan Pustaka, Kementerian Pendidikan Malaysia, 1995.

[11] Sheikholeslami, Mohsen, Ahmad Arabkoohsar, Ilyas Khan, Ahmad Shafee, and Zhixiong Li. "Impact of Lorentz forces on Fe304-water ferrofluid entropy and exergy treatment within a permeable semi annulus." Journal of Cleaner Production 221 (2019): 885-898. https://doi.org/10.1016/i.jclepro.2019.02.075

[12] Sheikholeslami, M., and D. D. Ganji. "Ferrofluid convective heat transfer under the influence of external magnetic source." Alexandria Engineering Journal 57, no. 1 (2018): 49-60. https://doi.org/10.1016/i.aej.2016.11.007

[13] Sheikholeslami, M., and S. A. Shehzad. "Thermal radiation of ferrofluid in existence of Lorentz forces considering variable viscosity." International Journal of Heat and Mass Transfer 109 (2017): 82-92. https://doi.org/10.1016/j.ijheatmasstransfer.2017.01.096

[14] Sheikholeslami, Mohsen, and Davood Domiri Ganji. "Ferrohydrodynamic and magnetohydrodynamic effects on ferrofluid flow and convective heat transfer." Energy 75 (2014): $400-410$. https://doi.org/10.1016/j.energy.2014.07.089

[15] Abdulwahab, Mohammed Raad, Nor Azwadi Che Sidik, Siti Nurul Akmal Yusof, and Muhammad Mahmud Jamil. "Magnetic Nanofluids for Heat Transfer Enhancement Inside Straight Channels." Journal of Advanced Research in Materials Science 68, no. 1 (2020): 8-19. https://doi.org/10.37934/arms.68.1.819

[16] Yasin, Siti Hanani Mat, Muhammad Khairul Anuar Mohamed, Zulkhibri Ismail, Basuki Widodo, and Mohd Zuki Salleh. "Numerical solution on MHD stagnation point flow in ferrofluid with Newtonian heating and thermal radiation effect." Journal of Advanced Research in Fluid Mechanics and Thermal Sciences 57, no. 1 (2019): 12-22.

[17] Mohamed, Muhammad Khairul Anuar, Nurul Ainn Ismail, Norhamizah Hashim, Norlianah Mohd Shah, and Mohd 
Zuki Salleh. "MHD slip flow and heat transfer on stagnation point of a magnetite $\left(\mathrm{Fe}_{3} \mathrm{O}_{4}\right)$ ferrofluid towards a stretching sheet with Newtonian heating." CFD Letters 11, no. 1 (2019): 17-27.

[18] Tiwari, Raj Kamal, and Manab Kumar Das. "Heat transfer augmentation in a two-sided lid-driven differentially heated square cavity utilizing nanofluids." International Journal of Heat and Mass Transfer 50, no. 9-10 (2007): 2002-2018. https://doi.org/10.1016/j.ijheatmasstransfer.2006.09.034

[19] El-Zahar, E. R., A. M. Rashad, W. Saad, and L. F. Seddek. "Magneto-hybrid nanofluids flow via mixed convection past a radiative circular cylinder." Scientific Reports 10, no. 1 (2020): 1-13. https://doi.org/10.1038/s41598-02072921-8

[20] Merkin, J. H. "Mixed convection from a horizontal circular cylinder." International Journal of Heat and Mass Transfer 20, no. 1 (1977): 73-77. https://doi.org/10.1016/0017-9310(77)90086-2

[21] Hussain, Shafqat, and Sameh E. Ahmed. "Unsteady MHD forced convection over a backward facing step including a rotating cylinder utilizing Fe304-water ferrofluid." Journal of Magnetism and Magnetic Materials 484 (2019): 356-366. https://doi.org/10.1016/i.jmmm.2019.04.040

[22] Brinkman, H. C. "The viscosity of concentrated suspensions and solutions." The Journal of Chemical Physics 20, no. 4 (1952): 571. https://doi.org/10.1063/1.1700493

[23] Maxwell, James Clerk. A treatise on electricity and magnetism. Vol. 1. Oxford: Clarendon Press, 1873.

[24] Yasin, Siti Hanani Mat, Muhammad Khairul Anuar Mohamed, Zulkhibri Ismail, and Mohd Zuki Salleh. "Mathematical Solution on MHD Stagnation Point Flow of Ferrofluid." In Defect and Diffusion Forum, vol. 399, pp. 38-54. Trans Tech Publications Ltd, 2020. https://doi.org/10.4028/www.scientific.net/DDF.399.38

[25] Singh, Ranjit J., and Trushar B. Gohil. "The numerical analysis on the development of Lorentz force and its directional effect on the suppression of buoyancy-driven flow and heat transfer using OpenFOAM." Computers \& Fluids 179 (2019): 476-489. https://doi.org/10.1016/i.compfluid.2018.11.017

[26] Toghraie, Davood, Seyed Mohammadbagher Alempour, and Masoud Afrand. "Experimental determination of viscosity of water based magnetite nanofluid for application in heating and cooling systems." Journal of Magnetism and Magnetic Materials 417 (2016): 243-248. https://doi.org/10.1016/j.jmmm.2016.05.092 